\title{
Korte signaleringen
}

\author{
HARRY A. POEZE
}

J. Thomas Lindblad en Alicia Schrikker (red.), Het verre gezicht: Politieke en culturele relaties tussen Nederland en Azië, Afrika en Amerika: Opstellen aangeboden aan prof.dr. Leonard Blussé. Franeker: Van Wijnen, 2011, 448 pp. ISBN 978.90.519.4422.8. Prijs $€ 45$.

Leonard Blussé (1946), opgeleid als sinoloog, ging in 2011 met emeritaat na een loopbaan sinds 1977 bij de Universiteit Leiden met meer dan tien jaar hoogleraarschap in de geschiedenis van de betrekkingen tussen Europa en Azië. Zijn publicatielijst is lang en bevat belangwekkende titels. Als enthousiaste promotor van internationale onderwijs- en onderzoeksprogramma's heeft hij grote verdienste. Het is passend dat zijn afscheid wordt gemarkeerd met een kloek, fraai uitgegeven vriendenboek: Het verre gezicht. Naast beknopte biografische informatie over en een bibliografie van Blussé bevat het boek 24 bijdragen van ongeveer vijftien bladzijden, solide voorzien van veel noten. Zij zijn geordend in rubrieken: De Indische Oceaan in de zeventiende eeuw - Java en Ceylon in de achttiende eeuw - Atlantische Oceaan - Het Verre Oosten - Nederlands-Indië - China en Nederland - Oost en West. Alle Leidse 'specialiteiten' op deze gebieden zijn vertegenwoordigd. Hun stukken zijn veelal leesbare miniaturen, vaak over kleurrijke individuen en vergeten episodes, met een flinke scheut culturele interactie.

De strijd van de VOC met Portugal om Ceylon rond 1640 wordt beschreven door Cátia Antunes en Lodewijk Wagenaar, terwijl Alicia Schrikker de evacuatie naar Batavia beschrijft van Nederlandse VOC-dienaren die na de Britse overname van Ceylon (1796) tien jaar lang daar verkommerden. Gerrit Knaap behandelt de daden van de kortstondige in het ambt overleden gouverneur-generaal Gerard Reijnst (1614-1615), Jaap Bruijn legt uit wat opperequipagemeesters in Batavia voor taken hadden en Willem Remmelink geeft nadere inhoud aan de betekenis en interpretatie van het verdrag van Giyanti (1755) tussen de VOC en de Sultan van Yogya. Remco Raben komt met nieuwe gegevens over de achtergronden van het Chinese verzet tegen de VOC dat uitliep op de Chinezenmoord van 1740. Over de opzet van de Nederlands-Indische staat door drie door koning Willem I benoemde commissarissen-generaal (1816-1819) vertelt Charles Jeurgens. Cees Fasseur verbindt de Indische-kolonisatieplannen - in een brochure uit 1844 - van Willem 
van der Hucht met de theecultuur in de Preanger en met de kennismaking van Douwes Dekker met zijn aanstaande echtgenote Tine van Wijnbergen. Kees van Dijk onthult dat de breuk tussen Van Heutsz en Snouck Hurgronje werd veroorzaakt door een verschil van mening over de aanleg van een paardenrenbaan in Atjeh en laat zien hoe belangrijk paardenraces waren als cultureel trefpunt. Wim van den Doel verschaft de biografie van de sociaaldemocratische bestuursambtenaar Wilhelm Middendorp die als Volksraadlid (1927-1930) een onversneden radicaal geluid liet horen, waarna van eigen collega's en de pers diepe verguizing zijn deel werd, met een onvermijdelijk vertrek tot slot. J. Thomas Lindblad vergelijkt de dekolonisatie van Indonesië en Maleisië - van raakvlakken, overeenkomsten tot steeds grotere verschillen.

In andere bijdragen wordt de VOC-vestiging in Deshima ruimschoots aandacht gegeven (Paul van der Velde, Ivo Smits) en richten op 'wereldschaal' Piet Emmer en Gert Oostindie zich op migratiestromen en koloniaal erfgoed. Een smet op de uitgave is het ontbreken van een register - de aard van het boek is geen excuus om dat na te laten.

Ben Koolen, VOC E onderwijs: Een inventarisatie. Assen: Boekwinkeltjes, 2011, 443 pp. ISBN 978.90.8748.008.0. Prijs $€ 19,95$.

VOC $\mathcal{E}$ onderwijs vormt de ingrijpende bewerking van Ben Koolen van zijn proefschrift uit 1993 (Een seer bequaem middel) tot een uitputtende inventarisatie van het schoolwezen zoals dat in twee eeuwen VOC-activiteit voorkwam. Het is een zeer bont beeld dat zo ontstaat, waarin de lokale kleuring de overeenkomsten en verschillen kenmerkt. De opzet is geografisch waarbij per regio per schooltype - primair en secundair - een overzicht wordt verschaft van de wederwaardigheden van de diverse scholen. Koolen begint in Nederland waar de VOC de particuliere opleiding van zeelieden, kaartenmakers en landmeters organiseerde en ook medisch personeel en 'ziekentroosters' opleidde. Een mislukt experiment vormde de uitzending van Molukse jongens naar Nederland. Een specifieke opleiding van predikanten voor Indië kwam niet goed van de grond. In de Oost waren er vijf regio's met aanzienlijke en duurzame onderwijsactiviteit, naast de wankele schooltjes elders, meestal bij VOC-nederzettingen. Dat waren Ambon, Batavia, Formosa, Ceylon en Kaap de Goede Hoop. Rond 1750 schat Koolen het aantal leerlingen op 5000 op Ambon, 10.000 op Ceylon, 2000 in Batavia en 1000 in de Kaapkolonie - Formosa was toen al verloren gegaan voor de VOC. Een groot verschil vormde de voertaal - Laag-Maleis in Ambon, Tamil in Ceylon, en Nederlands in Batavia en aan de Kaap.

De rol van de kerk is van groot belang, maar neemt in de loop der jaren af en is vooral sterk in Batavia. Uit allerlei bronnen heeft Koolen zijn gegevens 
bijeengeschraapt waarmee hij zijn overzicht invult. Zo mogelijk gaat hij in op schoolbestuur, schooltoezicht, leerplan, arbeidsvoorwaarden voor de onderwijzers, herkomst van leerlingen, lesrooster, leermiddelen en resultaten, dit alles ook neergelegd in allerlei tabellen. Het secundair onderwijs in de Oost is nog minder onder een bepaalde noemer te vangen. Wel zijn er in Ambon, Batavia en Ceylon scholen ter opleiding van predikanten en andere kerkelijke functionarissen opgezet, maar deze eindigden vrijwel alle voortijdig. Slechts die op Ceylon was een succes -17 studenten voltooiden zelfs hun opleiding in Nederland. En we leren ook dat De Kaap de primeur had van een kleuterschool, een bejaardenschool en een slavenschool.

De slotsom kan zijn dat Koolen met dit boek een op zijn grote kennis gebaseerd overzicht verschaft van het VOC-onderwijs - een waardevolle inventarisatie. En is hiervan nog iets beklijfd? Jawel, het Moluks Maleis als voertaal, in het bijzonder in Nederland, wellicht de Latijnse schrijfwijze van het Indonesisch, de 'burghers' op Ceylon en hun cultuur, en het Zuid-Afrikaans als taal. Het is niet uit te leggen dat in zo'n soort publicatie een register ontbreekt (het proefschrift bevatte een naam- en geografisch register).

Myriam Everard en Ulla Jansz (red.), De minotaurus onzer zeden: Multatuli als heraut van het feminisme. Amsterdam: Aksant, 2010, 175 pp. ISBN 978.90.5260.376.6. Prijs $€ 17,25$.

Aan de ruimschootse herdenking van 150 jaar Max Havelaar en 100 jaar Multatuli Genootschap droeg ook bij de bundel De minotaurus onzer zeden over Multatuli als heraut van het feminisme - de ondertitel van het boek. Multatuli had in zijn tijd grote invloed op de prille radicaal-feministische beweging, waarvan de pioniers zich lieten inspireren door zijn veelvuldige, maar verspreide schrijfsels daarover. Dat aspect van zijn maatschappelijke inzet is later ietwat vergeten, maar wordt overtuigend geschetst in deze bundel met zeven artikelen over vier vrouwen en twee mannen - feministen en multatulianen. Verspreid door het boek is er de Indische connectie te vinden, met name in het stuk over Mina Kruseman, en het meest uitgesproken in de bijdrage over Kartini en Multatuli, 'Een gedeelde mentale wereld' (pp. 147-66) van Jean Gelman Taylor. Kartini's aristocratische afkomst en het keurslijf waarin zij daardoor werd gedwongen perkten haar 'feminisme' drastisch in. Kartini was een groot bewonderaar van Multatuli, met kritiek op een aantal van zijn 'Indische' analyses en denkbeelden. Maar zij deelde met hem een mentale wereld, die van moederland en kolonie, waarin het woord nationalisme nog geen enkele rol speelde. De plaatsbepaling van Kartini in Indonesië en internationaal is het resultaat van geheel eigen krachten. Taylor zoekt, los daarvan, in deze bijdrage naar de oorspronkelijke positie van Kartini. 
Marita Mathijsen (red.), Boeken onder druk: Censuur en pers-onvrijheid in Nederland sinds de boekdrukkunst. Amsterdam: Amsterdam University Press, 2011, 207 pp. ISBN 978.90.8964.306.3. Prijs $€ 27,50$.

Boeken onder druk bundelt negen bijdragen over censuur in Nederland. Van preventieve censuur was slechts sprake tijdens de Franse (1810-1813) en Duitse (1942-1945) bezetting, maar repressieve vormen daarvan, formeel en informeel, op gevoelige gebieden als politiek, religie en seksualiteit, zijn in de Nederlanden sinds de boekdrukkunst toegepast. In Nederlands-Indië was dat anders, zoals Lisa Kuitert laat zien. Tot de uitvaardiging van het Drukpersreglemenrt in 1857 handelde het gouvernement naar willekeur - daarna was het Reglement tot zijn afschaffing in 1906 een machtig overheidswapen. Door het werk van Gerard Termorshuizen en Mirjam Maters is de perscensuur in Indië in kaart gebracht. Kuitert wil het niet eerder onderzochte effect van het Reglement op het verspreiden van boeken onderzoeken. Omdat de invoer van Nederlandse gedrukten vrij was - en Kuitert berekent dat in 1880 al een half miljoen boeken werden geïmporteerd - stond het gouvernement nogal machteloos in zijn controlepogingen. Voor in Indië gedrukte titels veel meer dan de enkele tientallen die Kuitert schat - lag dat anders. Kuitert noemt de censuur op Snouck Hurgronje's De Atjéhers, maar er zal meer te vinden zijn. En dat zeker ook ten opzichte van titels in inheemse talen, waarvan overigens de inhoud voor het Nederlandse bestuur bij gebrek aan taalexpertise vaak ontoegankelijk was. Al met al is dit artikel een voorproefje van wat een interessante publicatie kan opleveren.

Margaret Leidelmeijer (red.), Het verhaal van Indië. Arnhem: Indisch Herinneringscentrum Bronbeek, 2011, 64 pp. ISBN 978.94.90992.03.3. Prijs € 19,95.

Het verhaal van Indië, een tentoonstelling in het Indisch Herinneringscentrum Bronbeek vertelt de geschiedenis van de Nederlandse aanwezigheid in Indonesië, vooral voor de Nederlanders die daar werkten en woonden en hun nakomelingen.

De tentoonstelling, in augustus 2010 geopend, is veelgeprezen als een aantrekkelijke, indringende, gevarieerde en moderne museale overdracht van koloniale ervaringen. Het spreekt vanzelf dat de ingrijpende gebeurtenissen tijdens de Japanse bezetting en de dekolonisatie veel aandacht krijgen. Op verzoek van vele bezoekers is recent dit boek verschenen - geen catalogus van de tentoonstelling, maar een samenvatting, die ook door niet-bezoekers kan 
worden gelezen en doorgebladerd. De tekst is spaarzaam; de illustraties overheersen in een full-colour en fraaie opmaak. Vijf bekende 'Indische' auteurs leveren een column voor dit mooie boekje.

Esther Zwinkels, Het Overakker-complot: Indisch verzet tegen de Japanse bezetter op Sumatra 1942-1945. Houten-Antwerpen: Unieboek-Het Spectrum, 2011, 368 pp. ISBN 978.90.491.0699.7. Prijs $€ 24,99$.

Het Nederlands-Indische Leger (KNIL) capituleerde al spoedig na de Japanse aanval. Op Java werd de overgave op 8 maart 1942 getekend. De troepen op Sumatra zetten de strijd nog voort, maar beëindigden hun hopeloos verzet op 28 maart. De beide commandanten, R.Th. Overakker (1890-1945) en G.F.V. Gosenson (1888-1945), gaven opdracht een illegaal netwerk te vormen dat vooral tot doel kreeg de geallieerden te steunen bij de spoedig verwachte heroveringsoperatie. Tot de taken behoorden ook het opslaan van wapens en het verzamelen van inlichtingen voor de geallieerden. Gosenson was zelfs van plan guerrillaverzet te organiseren. Een groep van KNIL-militairen slaagde er in in Atjeh een jaar lang uit Japanse handen te blijven, maar kwam niet tot gewapende actie. Overakker en Gosenson werden afgevoerd naar Formosa. Voor hun vertrek legde Overakker schriftelijk vast wie het verzet moest leiden.

Esther Zwinkels geeft in Het Overakker-complot - een bewerking van haar doctoraalscriptie - een gedetailleerd overzicht van alle verwikkelingen rond dit verzet. Zij won er de Erik Hazelhoff Roelfzema Prijs mee, waarvan ook publicatie van de bekroonde studie onderdeel vormt. Het verzetsnetwerk was overigens een los-vaste verzameling van groepen, die op amateuristische wijze activiteiten probeerde te ontplooien. Zwinkels' schatting is dat 230 personen waren betrokken met een mogelijk in te schakelen achterban van 600 personen. Het waren niet alleen militairen, maar ook gedemobiliseerde dienstplichtige Nederlanders, artsen en verplegers - ook vrouwen - en Molukkers, Chinezen en Indonesiërs. Het was vooral passief verzet, dat geen duidelijk doel kende. De Japanse militaire politie Kempeitai, was zeer alert en wantrouwend ten opzichte van ongewenste activiteiten van geïnterneerde Nederlanders en mogelijke sympathisanten daarbuiten. Al in december 1942 werden aanhoudingen verricht, van wat de Kempeitai als de organisatie Rode Zakdoek aanduidde. Onderzoek volgde, met fysieke en psychische marteling, en de ontmanteling van het gehele netwerk met bijna zeshonderd arrestanten was al enkele maanden later het geval. De eerste rechtszaken vonden plaats en de eerste doodvonnissen werden voltrokken. Overakkers benoemingsbesluit werd gevonden en hij en Gosenson werden ter berechting 
overgebracht naar Sumatra. Ze werden weer uitgebreid verhoord en verschenen uiteindelijk pas op 9 januari 1945 voor hun rechters. Zij werden ter dood veroordeeld en dezelfde dag geëxecuteerd.

Vrijwel alle Japanse dossiers over onderzoek en berechting van geallieerde verzet zijn vernietigd. Door een gelukkig toeval is het dossier van het complot-Overakker bewaard gebleven. Op basis van de Engelse vertaling (vierhonderd bladzijden) kon Zwinkels de gang van zaken ontrafelen. Zij doet dat gedegen, uitputtend en leesbaar.

Haar conclusies zijn voorzichtig. Het procesverslag, inclusief de resultaten van het onderzoek naar het verzet, zijn redelijk betrouwbaar. Procesgang en vonnis zijn niet op willekeur gebaseerd. Tot slot gaat Zwinkels nog in op naoorlogse waardering voor de daden van Overakker en Gosenson en hun ondergeschikten. Het verschil met het Nederlandse verzet is groot. De invulling van Indische heldendaden en schurkenstreken is warrig, ondanks de commissies die zich hierover bogen. Deze conclusie werkt zij nader uit in een nog te volgen publicatie.

Peter Schumacher, Ogenblikken van genezing: De gewelddadige dekolonisatie van Indonesië. Herziene editie. Amsterdam: Van Gennep, 2011, 375+16 pp. ISBN 978.94.6164.042.0. Prijs € 24,99.

Peter Schumacher (1933) werd geboren en groeide op in Indië en geïnterneerd in een Japans kamp (1943-1945). Hij repatrieerde in 1950 naar Nederland, toen nog vol wrok tegen de Indonesische nationalisten. Zijn lange loopbaan als journalist, waarbij zijn correspondentschap in Jakarta in 1971 eindigde toen hij door het Soehartobewind werd uitgewezen, sloot hij af als redacteur van NRC Handelsblad. Hij gaf in 1996 in Ogenblikken van genezing zijn visie op de geschiedenis van de dekolonisatie van Indonesië tegen de achtergrond van zijn Indische jeugd, de traumatische kampervaringen en zijn eigen politieke ontwikkelingsgang. Onder dezelfde titel, die de lezer wellicht doet denken dat hij met een 'self-help'-boek van doen heeft, maar voorzien van de ondertitel De gewelddadige dekolonisatie van Indonesië, is een ingrijpend herziene herdruk van dit boek verschenen. Gebleven is de vermenging van eigen ervaringen en historische feiten en ontwikkelingen, met veel oog voor het saillante detail en nieuwe feiten, gebaseerd op eigen onderzoek en interviews met ooggetuigen. Op die manier worden mannen als Christison, Van Mook, Spoor, Westerling en vele anderen voor een deel in nieuw licht gesteld. In de herdruk is er veel aandacht voor de nasleep van de dekolonisatie: de opheffing van het KNIL, de Molukse kwestie, het Nieuw-Guineaconflict en de opvang van de Indische Nederlanders en hun koloniale erfenis, met 'backpay' 
en Het Gebaar als trefwoorden. In aangenaam leesbare vorm verschaft Schumacher zo, met veel aandacht voor de 'Indonesische' kant van het conflict, een overzicht van de Indonesische dekolonisatie.

Esther Captain en Guno Jones, Oorlogserfgoed overzee: De erfenis van de Tweede Wereldoorlog in Aruba, Curaçao, Indonesië en Suriname. Amsterdam: Bert Bakker, 2010, 433 pp. ISBN 978.90.351.3584.0. Prijs € 19,95.

Het NWO-onderzoeksprogramma 'Oorlog, erfgoed en herinnering: een dynamisch perspectief' levert met Oorlogserfgoed overzee een dik boek op waarin Esther Captain voor Aruba/Curaçao en Indonesië en Guno Jones voor Suriname uiteenzetten wat de erfenis van de Tweede Wereldoorlog in deze voormalige Nederlandse koloniën inhoudt. Zij laten zien in welke vormen het oorlogserfgoed overzee voorkomt en welke betekenis deze hebben. Daarbij is sprake van een voortdurend proces van veranderende interpretaties - passend bij een omschrijving van erfgoed als de verbinding van het eigen verleden met eigentijdse overtuigingen en bedoelingen. Met het overlijden van de laatste bewuste ooggetuigen verschuift het accent naar materieel en immaterieel erfgoed, maar lijkt de belangstelling niet terug te lopen. Erfgoed speelt een grote rol in de bepaling van de nationale identiteit, waarbij de Tweede Wereldoorlog als ijkpunt en bepalende factor fungeert. Dat geldt in Nederland, waarbij ook de drie miljoen Nederlanders zijn betrokken van buiten-Nederlandse achtergrond. Hun invloed op de inhoud van het erfgoed leidt er toe dat in algemene zin het nationale draagvlak wordt vergroot.

Voor Indonesië was de Wereldoorlog vooral de opmaat tot de succesvolle nationale revolutie. De voorafgaande Japanse bezetting en de voor de Nederlanders diep ingrijpende kampervaringen of repressie buiten de kampen zijn in het Indonesische nationale bewustzijn vergeten gebeurtenissen. Voor de koloniën in de West waren de omstandigheden onvergelijkbaar anders. Het enige raakvlak van oost en west was de inzet van 450 Surinaamse vrijwilligers in de strijd tegen Japan op Nieuw-Guinea en Borneo (1944-1947), die als erfgoed grote symbolische betekenis verkreeg. Captain richt zich in de twee 'Indonesische' hoofdstukken (90 bladzijden) allereerst op het overvloedige erfgoed in Yogyakarta, de hoofdstad van de Republik Indonesia tijdens de Revolutie. Zij verkent de verschillen tussen de regimes van Soekarno en Soeharto in hun benadering van de Revolutie, met bijvoorbeeld aandacht voor het gebruik van reliëfs en diorama's. Ook de controverse over de rol van Soeharto bij een grootscheepse aanval op het door Nederland bezette Yogya in 1949 wordt beschreven. De eer die Soeharto zich hiervoor toe-eigende ten koste van de 
Sultan van Yogya is sinds Soeharto's aftreden flink aangepast. In Ambarawa en Banyubiru ging Captain op zoek naar de nauwelijks vindbare restanten van de interneringskampen daar. Buiten de erevelden is er zeer weinig te vinden. Niettemin zijn 'nostalgiereizen' al decennia populair. Recent verschenen er zelfs twee specifiek hierop toegespitste reisgidsen (Reisgids Indonesië; Oorlogsplekken 1942-1949, met inbreng van Captain, gesignaleerd in Bijdragen 163, 2010, p. 378; Emile Leushuis, Gids historische stadswandelingen Indonesië, gesignaleerd in Bijdragen 164, 2011, pp. 379-80). Bijzonder is Captains hoofdstuk over erfgoed op Biak. De zware Amerikaans-Japanse gevechten daar in 1944 hebben tot een gedenkteken en een particulier museum geleid, maar ook tot regelmatig bezoek van Japanse en Amerikaanse veteranen en hun verwanten, die hun kameraden en familieleden daar herdenken. De Japanse overheid is er in geslaagd in samenwerking met Indonesische instanties vijftig herdenkingsplekken te markeren; Nederland is dat nog nergens gelukt. Captain en Jones hebben hun verhaal op een niet eerder op samenhangende wijze geëxploreerd terrein helder verteld en zij openen zo nieuwe vergezichten.

Casper van Bruggen, 'Verget ons niet': Het Papoea Vrijwilligers Korps (1961-1963). Soesterberg: Aspekt, 2011, 315 pp. ISBN 978.94.6153.004.2. Prijs € 22,95.

Binnen de Nederlandse dekolonisatieplannen van West-Nieuw-Guinea paste ook de vorming van een eigen leger, samengesteld uit Papoea's. Het duurde heel lang voor die plannen vaste vorm kregen. Het succesvolle Papoeabataljon dat grote verdienste had in de laatste fase van de Pacific-oorlog en toen duizend man telde werd snel ingekrompen en in 1954 opgeheven. In de semimilitaire Algemene en Mobiele Politie waren Papoea's opgenomen, maar voor strikt militaire taken was slechts de Koninklijke Marine en het Korps Mariniers aanwezig. Het Pacific Islands Regiment in Papua New Guinea leverde de inspiratie voor de opzet van het Papoea Vrijwilligers Korps (PVK). De latere commandant kolonel W.A. van Heuven leverde begin 1961 een rapport af dat vrijwel meteen - op 23 februari 1961 - resulteerde in het officiële oprichtingsbesluit. Even voorvarend werd de rekrutering gestart, met werving in alle delen van het eiland, en werd een kazerne gebouwd in Manokwari. Zestig man Nederlands kader leidde vijf bataljons van dertig man op. Een nieuwe lichting van 170 man kwam niet veel verder dan het begin van oefening. In november 1961 vond de officiële installatie plaats. In maart 1962 werden de pelotons ingezet tegen Indonesische infiltranten die de Indonesische eis tot overdracht kracht moesten bijzetten. Tot aan de wapenstilstand in augustus 1962 leverde het PVK, dat een meester was in terreinkennis, spoorzoeken, ver- 
kennen en hinderlagen leggen, zijn aandeel in het opsporen, uitschakelen en gevangennemen van de Indonesische militairen. De overdracht aan Indonesië kwam voor de PVK-militairen als een schok. De PVK werd per 1 oktober 1962 opgeheven. Binnen VN-verband was het nog actief tot mei 1963. Een deel ging over in Indonesische dienst, anderen zijn een paar jaar later terug te vinden in het gewapende Papoeaverzet tegen het Indonesische bestuur.

Over het PVK is nooit iets van grotere omvang gepubliceerd. Casper van Bruggen, conservator bij het Legermuseum, heeft dat goedgemaakt in 'Verget ons niet', een gedetailleerd verslag van dit kortstondige curieuze legeronderdeel. Archivalia, interviews en literatuur zijn ten volle benut voor een gedetailleerd, levendig, overvloedig geïllustreerd verslag van vorming, opleiding en inzet van het PVK - voorzien van de nodige bijlagen, namenlijsten en registers.

Victor Kaisiëpo Msn, Een perspectief voor Papoea's: Het verhaal van mijn leven en mijn strijd. Opgetekend door Willem Campschreur. Amsterdam: KIT Publishers, 2011271 pp. ISBN 978.94.6022.1149. Prijs $€ 19,50$.

Victor Kaisiëpo (1948-2010) vertelde toen hij wist dat hij nog kort te leven had zijn levensverhaal aan Willem Campschreur, die in Een perspectief voor Papoea's dat vastlegde en rangschikte. In ik-vorm wordt Kaisiëpo gevolgd, van zijn traditionele dorp op Biak, waar zijn vader Marcus Kaisiëpo al een man van gezag is naar Hollandia. Hier behoort Marcus met Nicolaas Jouwe tot de belangrijkste Papoealeiders die het Nederlandse bestuur inzet om overdracht aan Indonesië te voorkomen met uitzicht op een onafhankelijke Melanesische staat. In 1962 komt het tot de onvermijdelijke overdracht en wordt het gezinKaisiëpo halsoverkop afgevoerd naar Nederland. Marcus Kaisiëpo en Jouwe blijven zich vergeefs en in eindeloze onderlinge vete keren tegen Indonesië, des te uitzichtlozer nadat Indonesië in 1969 een farce maakte van de volksraadpleging over een onafhankelijk Papua. Zoon Victor ruilde een tropische jeugd in voor een koude middelbare school in Zuid-Holland en een administratieve baan. Hij maakte zich in de jaren zeventig los van de bestaande bannelingenkring en werd actievoerder in breder verband: het Komitee Indonesië en internationale organisaties, waaronder de Verenigde Naties die zich inzetten voor de zaak van de 'inheemse volken'. Daarnaast stond hij aan de wieg van het West-Papua Volksfront (1984) en de Stichting Papua Volken (1991). Politieke actie ging samen met culturele manifestaties - Victor was onvermoeibaar en verscheen op talloze conferenties als pleitbezorger voor de Papoea en andere inheemse volken. Na drie jaar voor een milieu-NGO in Fiji keerde hij terug naar Nederland. De val van Soeharto opende onvermoede 
perspectieven. Van 2000 tot zijn dood bezocht Victor zestien maal Papua, waar de hoge verwachtingen op een onafhankelijk bestaan na het aantreden van president Megawati werden gefnuikt. De charismatische Victor was erbij, gaf raad en vertegenwoordigde NGO's. In een slotbeschouwing zet hij zijn ideeën uiteen over de toekomst voor Papua, waarin hij de bestaande situatie onder Indonesisch bestuur als een realiteit aanvaardt. Vijftig jaar Jakarta kan niet worden miskend, maar vormt ook geen reden de status quo te aanvaarden of onafhankelijkheidsidealen te begraven. Hij bekent zich daarbij tot de ondertitel van de gezaghebbende publicatie: Papua Road Map; Negotiating the past, improving the present and securing the future (2008). 